\title{
A GREEN CORRIDOR BALANCED SCORECARD
}

\author{
Gunnar Prause \\ School of Economics and Business Administration, Tallinn University of Technology \\ Akadeemia tee 3-370, 12618 Tallinn, Estonia \\ Phone: + 372620 3971, e-mail: gunnar.prause@ttu.ee
}

\begin{abstract}
Green transport corridors represent trans-shipment routes with a concentration of freight traffic between major hubs and long distances of transport marked by reduced environmental and climate impact. Important characteristics of green corridors are their network structures, their transnational character and their high involvement of public and private stakeholders, including political level requiring new governance models. Network-oriented controlling of green transport corridors require new concepts and instruments concentrating on multi-dimensional evaluation of collective strategies and processes in an international environment with a focus on cross-company aspects.

Until now the scientific discussion focusses on different sets of Key Performance Indicators (KPI) for monitoring and management of green corridors, which mainly cover sustainable aspects of green corridor development by neglecting a networkoriented controlling approach so that a general concept for green corridor controlling is still missing. The current KPI approaches emphasize the operational aspects of the corridor performance so that a strategic management control system is needed to safeguard an efficient, innovative, safe and environmental friendly long-term development.

The paper will present and discuss a management control system for green supply chains based on the balanced scorecard concept and link the ongoing scientific discussion to recent research results about green corridor management. The presented green corridor balanced scorecard tries to solve the strategic weakness of the existing green corridor controlling approaches by integrating cooperative and network-oriented concepts from supply chain management.
\end{abstract}

Keywords: Green Transport Corridors, Management Control Systems, Networks, Balanced Scorecard, Key Performance Indicators

\section{Introduction}

Since the EU White Paper on Transport in 2011 the concept of green transport corridors enjoys high attention in the EU transport policy development. Green transport corridors can be characterized as European trans-shipment routes with concentration of freight traffic between major hubs and relatively long distances of transport marked by reduced environmental and climate impact, while increasing safety and efficiency with application of sustainable logistics solutions, inter-modality, ICT infrastructure, common and open legal regulations and strategically placed trans-shipment nodes. In order investigate and implement the green corridor concept the EU Commission initiated several EU-funded regional development projects to realize different approaches and ideas of this concept.

The main characteristics of green transport corridors are related to green or sustainable aspects, multimodality and network concepts (Hunke and Prause, 2013; Prause and Hunke, 2014b), so green supply chain management represents one important source for the theoretical foundations. In the context of green supply chain management, there exists interdependency between conventional supply chain management and eco-programs (Sarkis, 2001). This includes the approach on how ecological aspects can be considered in the whole business processes in the most effective way.

When it comes to management control systems for supply chains a literature review reveals that specific controlling topics in this context have been discussed by several scholars but no integral theory or conceptual framework papers about supply chain controlling exist in the leading English speaking supply chain journals except the article of Seuring (2006), who introduced in the German supply chain controlling concepts explaining the dominance of references of German scholars in this field. Consequently, a comparable situation can be stated for green supply chains and green corridors, which have gained attention in recent years but beside the discussion of certain controlling tools still no single concept or theory exists in this field (Seuring and Müller, 2008; Göpfert, 2013).

Since green corridors are imbedded into an international network environment new concepts and instruments concentrating on multi-dimensional evaluation of collective strategies and processes are required, taking into account international and cross-company aspects, but such a network-oriented controlling is still in the beginning (Sydow and Möllering, 2009). A widespread approach for a networkoriented controlling is based on the balanced scorecard concept of Kaplan and Norton (1996), which has been transferred and adapted to a cross-company interactions leading to "cooperative scorecards" of “network-balanced scorecards" (Hippe, 1997; Lange et al., 2001; Hess, 2002). 
The current scientific discussion related to performance monitoring of green corridors focusses on different sets of Key Performance Indicators (KPI) for management of green corridors, which are mainly covering sustainable aspects of green corridor development by neglecting a network-oriented controlling approach so that a general concept for green corridor controlling is still missing. Furthermore, the KPI approach emphasizes the operational aspects of the corridor performance so that a strategic management control system is needed to safeguard an efficient, innovative, safe and environmental friendly long-term development.

The paper will present and discuss a balanced scorecard approach for green corridors and link the results to the ongoing scientific discussion about green supply chain management. In order to solve the strategic weakness of the existing management control concepts for green corridor the new green corridor balanced scorecard approach will integrate cooperative and network-oriented concepts. The scientific discussions will be shown that this green corridor balance scorecard approach has potential to serve as a suitable controlling instrument for managing an effective and efficient green corridor development, which is independent of specific governance models.

\section{Supply Chain Controlling}

One way to characterize a transport corridor is to understand the corridor as a conglomeration of different stakeholders, which act along a defined geographical area in order to achieve different goals but with the same objective to reduce costs, increase efficiency, minimize environmental impact and create safe and sustainable logistics solutions (Hunke and Prause, 2013; 2014a). This approach based on the interaction of acting organisations along their supply chains in the corridor stresses a network perspective from organisation's point of view on the collaborative practices and integrative behaviours of the stakeholders in the supply chains (Lee, 2005). As the stakeholders act in a coherent sense and are located in a certain geographical area a green transport corridor can be described as a tubular service cluster.

An interesting example for a green transport corridor is the East-West Transport Corridor (EWTC), linking Southern Sweden, Lithuania, Belarus and Ukraine, where the tubular cluster has the following shape (Prause and Hunke, 2014b):

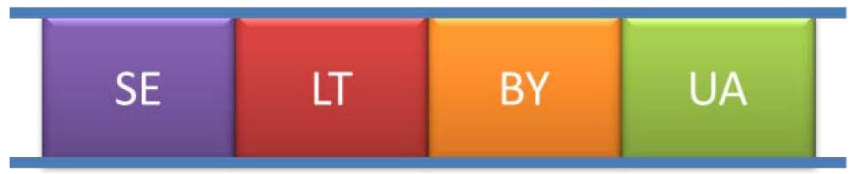

Figure 1. Green transport corridor as a tubular service cluster

Source: Prause and Hunke, 2014a

Figure 1 highlights already that the network-oriented consideration of a green transport corridor concerns questions like intercultural issues related to different business cultures and models as well as different legal systems, which are beyond ordinary network topics like collective processes and strategies of the heterogeneous set of network stakeholders. Therefore, for the monitoring and controlling of those networks there are instruments required, which are able to evaluate these collective strategies and processes related to the demand of a holistic coverage, planning and development for such networks.

Ackermann (2003) proposed for the controlling of a supply chain a "supply chain balanced scorecard", where the traditional perspectives related to finance, processes, clients and learning are still maintained but they are oriented on the integral supply chain instead on unique companies or stakeholders. Weber (2002) took one step further and created cross-company balanced scorecard for a supply chain, which keeps the two traditional perspectives finance and processes but he replaced the other two traditional perspectives by two new ones, which he called cooperation intensity and cooperation quality:

- Financial perspective,

- Process perspective,

- Cooperation intensity, and

- Cooperation quality.

In his proposal Weber subsumed under the cooperation intensity perspective the "hard factors" of cooperation like data exchange, whereas he used the cooperation quality to focus on the "soft factors" like trust. Weber's proposal for a supply chain balanced scorecard has the following structure: 


\begin{tabular}{|c|c|c|c|}
\hline Perspective & Strategic target & Indicator & Measures \\
\hline \multirow{2}{*}{$\begin{array}{l}\text { Financial } \\
\text { Perspective }\end{array}$} & Increase return of $\mathrm{SC}$ & Increase RoA of SC by $\times \%$ & $\begin{array}{l}\text { Outsource warehousing } \\
\text { Reduce working capital }\end{array}$ \\
\hline & Try to achieve cost ledership & $\begin{array}{l}\text { Reduce logistics costs in } \\
\text { SC per unit by } x \%\end{array}$ & $\begin{array}{l}\text { Bundling of partner } \\
\text { capacities }\end{array}$ \\
\hline \multirow[t]{2}{*}{$\begin{array}{l}\text { Process } \\
\text { Perspective }\end{array}$} & Max. lead time client: 10 days & $\begin{array}{l}\text { Reduce } S C \text { lead time to } \\
10 \text { days }\end{array}$ & $\begin{array}{l}\text { Cross partner process } \\
\text { optimization }\end{array}$ \\
\hline & $\begin{array}{l}\text { Increase flexibility of } \\
\text { operations }\end{array}$ & $\begin{array}{l}\text { Increase freezing point in } \\
\% \text { of lead time of SC }\end{array}$ & $\begin{array}{l}\text { Flexible parts, } \\
\text { postponement }\end{array}$ \\
\hline \multirow{2}{*}{$\begin{array}{l}\text { Perspective of } \\
\text { Cooperation } \\
\text { Intensity }\end{array}$} & $\begin{array}{l}\text { Increase data exchange } \\
\text { between SC partners }\end{array}$ & $\begin{array}{l}\text { Number and frequency of } \\
\text { exchanged data sets }\end{array}$ & $\begin{array}{l}\text { Improve IT - networking } \\
\text { of SC partners }\end{array}$ \\
\hline & $\begin{array}{l}\text { Increase coordination between } \\
\text { SC partners }\end{array}$ & $\begin{array}{l}\text { Number of necessary } \\
\text { coordination meetings }\end{array}$ & $\begin{array}{l}\text { Systematic management } \\
\text { of notes and minutes }\end{array}$ \\
\hline \multirow{2}{*}{$\begin{array}{l}\text { Perspective of } \\
\text { Cooperation } \\
\text { Quality }\end{array}$} & $\begin{array}{l}\text { Increase trust and satisfaction } \\
\text { level between SC partners }\end{array}$ & $\begin{array}{l}\text { Establish indicators for } \\
\text { trust and satisfaction }\end{array}$ & $\begin{array}{l}\text { Define common visions } \\
\text { and guidelines }\end{array}$ \\
\hline & Increase cooperation quality & $\begin{array}{l}\text { Number of uncooperative } \\
\text { solved conflicts }\end{array}$ & $\begin{array}{l}\text { Establish "referee" for } \\
\text { the SC }\end{array}$ \\
\hline
\end{tabular}

Figure 2. Weber's modified Supply Chain Balanced Scorecard Source: Sydow and Möllering, 2013

Together with his proposal Weber (2002) pointed out that a large number of proposed scorecards for the evaluation of supply chains are only slightly modified classical balanced scorecards without any significant network perspective. The challenge to find an appropriate approach for an effective network controlling lies in the fact that networks are rather dynamic structures, whereas most of the existing controlling concepts are rather targeting on stable structures, so that more flexible management control systems are needed (Sydow and Möllering, 2013).

\section{Monitoring of Green Corridor Performance}

Most of the green corridor initiatives represent EU-funded regional development projects due to the political background of the green corridor concept with its links to the EU White Paper on Transport 2011. Consequently, the implementations of green transport corridors are based of different understandings and realizations of the concept making it necessary to evaluate, compare and benchmark existing green corridor implementations.

Already for the monitoring of green transport corridors there are many different attempts starting from individual companies and industry representatives up to international government level. An important case was the EU-funded project "EWTC2" within the BSR Interreg IVB Programme, where for the first time a "Green Corridor Manual" based on the East-West-Transport-Corridor was developed trying to give a holistic and consistent monitoring concept for multi-modal sustainable transport (Hunke and Prause, 2013). An important element of the Green Corridor Manual was a proposal for a set of Key Performance Indicators (KPI), which measures different aspects of the performance of transport chains.

The set of KPI can be separated into two subsets of indicators measuring enabling and operational criteria. The enabling indicators describe the settings and characteristics of the transport chain in regard to the hard infrastructure. The operational indicators characterise the soft infrastructure including the information and communication systems, which support the transport logistics services, the aspects related to regional, national and international policies and the set of regulations, which apply to all stakeholders. In this sense, operational aspects describe the geographical settings as such, the transport and logistics solution by involving new and innovative business models. The implementation of transport techniques will have also a direct impact on the performance of a transport chain measured by given KPIs.

\begin{tabular}{|l|l|l|}
\hline Performance areas & Operational indicators & Enabling indicators \\
\hline Economic efficiency & $\begin{array}{l}\text { Total cargo volumes } \\
\text { On time delivery }\end{array}$ & Corridor capacity \\
\hline Environmental efficiency & $\begin{array}{l}\text { Total energy use } \\
\text { Greenhouse gases, Co2e } \\
\text { Engine standards } \\
\text { ISO } 9001 \text { dangerous goods }\end{array}$ & Alternative fuels filling stations \\
\hline Social efficiency & $\begin{array}{l}\text { ISO 31000 } \\
\text { ISO } 39000\end{array}$ & $\begin{array}{l}\text { Safe truck parking } \\
\text { Common safety rating } \\
\text { Fenced terminals }\end{array}$ \\
\hline
\end{tabular}

Figure 3. Performance Indicators

Source: EWTC2 Green Corridor Manual, 2012 
Figure 3 gives an overview about the KPIs, which were selected from the EWTC2 project and which have been tested during the project life-time. As can be seen from the table the performance areas of the EWTC2 KPI system are covering economic, environmental and social dimensions.

Additionally to the table of performance indicators, often in a more detailed way the enabling factors are described by a corridor dashboard aiming at connecting the short-term KPIs and enabling KPIs by visualizing capacity, accessibility and performance. Thus, the dashboard stimulates improvements of the corridor infrastructure and facilitates the cooperation of all stakeholders along the corridor in order to improve total performance (EWTC2 Green Corridor Manual, 2012).

There are different aspects influencing the performance of a green transport corridor. In the EWTC approach proposes a KPI based on economic, environmental and social aspects representing the three dimensions of efficiency (EWTC 2012). But the KPI system of EWTC emphasises hard factors whereas the soft factors are neglected. Prause (2014b) illustrated that the performance of green transport corridors depends heavily on the long-term success of their underlying hubs, representing logistics clusters, and the sustainable development of these logistics clusters is strongly impacted by the "soft factors", which are usually linked to the cluster governance.

The importance of soft factors in the context of green transport corridors also appear due to its multi-modal nature. Sanders and Premus (2002) stressed the function of information in supply chain management as glue that hold the collaborating business structures in the supply chain together and Evangelista (2002) stated that the role of ICT in supply chain management can be described as key integration element. Daduna et al. (2012) pointed out that intermodal transport is built of networks of logistics companies and components so their management depends on powerful ICT-systems. All these results show the relevance of "soft factors" like trust, inter-cultural skills, innovation and cooperation skills for the long-term success of green corridors.

An important and successful case for a green transport corridor concept is the EWTC business model that is based on multi-modal logistics solution and that offers a value proposition towards the client (Kusch et al., 2011). The EWTC corridor offers full logistics service for the shipment of 20, 40, 45 feet containers, trailers, semi-trailers and trucks with a fixed schedule and pricing between Klaipeda in Lithuania and Ilyichevsk near Odessa in Ukraine. The full logistics services are offered via an one - stop - shop (EWTC-OSS; http://www.vikingtrain.com ) to the integrating the logistics services around the shuttle train "Viking" which realises the container transport between Klaipeda and Ilyichevsk with a 46\% cost savings for compared to a truck transportation within a fixed time of $52 \mathrm{~h}$ including border crossing and customs procedures. This offer is not only cheaper and faster than normal truck transportation; it also is greener due to the use of train transport.

\section{Framework conditions of Green Transport Corridors}

In order to characterise the framework conditions for green transport corridors it is important to get familiar with the main results of some of the most important logistics development project in the Baltic Sea Region. The starting point of all later green corridor initiatives was the BSR Interreg IIIB project "LogOn Baltic - Developing Regions through Spatial Planning and Logistics \& ICT Competence", which was implemented 2006-2007 and aimed at depiction of the logistics status in the BSR after the EU enlargement in 2004. The empirical activities of LogOn Baltic showed that the landscape of intercompany logistics was dominated by larger production companies and logistics service providers together with their closed and company oriented ICT-systems in order to safeguard the control of their individual supply chains and to realise dedicated platforms for sourcing of transport services mainly from regional SME (Kersten et al., 2007; Kron and Prause, 2008).

The second important initiative with a strong impact on the green corridor activities in the BSR was led by the Swedish Logistics Forum and resulted into the formulation of six requirements on green corridors (Green Corridor, 2010):

- Sustainable logistics solutions with documented reductions of environmental and climate impact, high safety, high quality and strong efficiency;

- Integrated logistics concepts with optimal utilization of all transport modes, so called comodality;

- Harmonized regulations with openness for all actors;

- A concentration of national and international freight traffic on relatively long transport routes;

- Efficient and strategically placed trans-shipment points, as well as an adapted, supportive infrastructure; and 
- A platform for development and demonstration of innovative logistics solutions, including information systems, collaborative models and technology.

The six framework conditions comprise a couple of important characteristics for the organisation and structuring of green transport corridors. Since the stakeholders within a green corridor are composed of different institutions including public and private organisations of different size and intention, of special importance for the SME sector is the demand of "openness and harmonization for all actors" as well as "collaborative models and technology" stressing a more balanced and cooperative work of all kind of stakeholders in the green corridor.

The set of framework conditions of the Swedish Logistics Forum have to be completed by a set of quantitative indicators to allow the monitoring and controlling of the performance and development of the Green Transport Corridor. Here the two EU projects "SuperGreen" and "EWTC2" developed and delivered for the first time proposals for KPI (Hunke and Prause, 2013). Especially the "Green Corridor Manual" of the EWTC2 project fixed a set of recommendations and guidelines on how to implement the green corridor concept according to the EU freight agenda and as promoted by the EU Baltic Sea Strategy and trying to give a holistic and consistent monitoring concept for multi-modal sustainable transport (EWTC2 Green Corridor Manual, 2012). The EWTC approach was based on the results of the green corridor initiative of the Swedish Logistics Forum and the FP7 - project "SuperGreen".

A more detailed picture about the framework conditions of green corridors can be drawn by analysing the requirements for logistics ICT systems and in particular about integrated green corridor ICT systems. Already the results of the comparison of regions within the LogOn Baltic project brought to light that the BSR regions with higher logistics competence enjoyed a higher degree of ICT usage in logistics together with a significant higher level of outsourced logistics ICT services, but the outsourcing of logistics ICT solutions was laid on closed and company oriented systems (Kron and Prause, 2008). Expert interviews revealed that the landscape of inter-company logistics ICT systems was dominated by larger production companies and logistics service providers to safeguard the control of their individual supply chains and to realise dedicated platforms for sourcing of transport services mainly from regional SMEs (Prause et al., 2010).

In a comparable analysis Prause and Hunke (2014) summed up the main results and properties of the ICT systems of green corridor initiatives from BSR in order to formulate system requirements for an integrated green corridor ICT system. The analysis was able to fix a set of functionalities, technical requirements and organizational frame conditions for such integrated green corridor ICT systems:

- Open architecture,

- Oriented on standards,

- Focus on inter-operability and co-modality,

- Independence of technology,

- Endorsed and adopted by major freight ICT-systems providers and logistics operators,

- Support the European transport and logistics system to be more efficient and environmentalfriendly, and

- Creation of a fair and balanced transport spot market within the corridors enabling market leaders and SMEs to interact at a low cost.

Especially the realization of the last condition represents a task far beyond a technical question, since the implementation is related to the political question of convincing the current big logistics players to open their closed ICT systems and to integrate these systems into the common logistics platform of the green transport corridor, which is directly related to a loss of their influence and market power.

Another rather political challenge for the whole green corridor is related to the creation of an open data base within the green corridor ICT system comprising freight tariffs and contracting conditions in order to be able to build green corridor spot market for logistics services. This requirement is related to the implementation of openness, transparency and trust among the stakeholders, which is rather an organizational or political task belonging to the sphere of the "soft factors" of the green corridor.

\section{Indicators for Soft Factors}

Weber's proposal was oriented on the needs of supply chains but like Prause (2014) proposed, due to the conventional proximity between supply chains and green corridor, to use Weber's ideas for constructing a green corridor balanced scorecard which includes the KPI system of the EWTC "Green Corridor Manual" and which respect also the frame conditions of green transport corridor. Prause and Hunke (2014b) exhibited that beside the criteria covered by be EWTC key performance indicators also 
other aspects like openness, transparency, fair and harmonised access regulations as well as cooperation aspects are common and characteristic frame conditions for green transport corridors which have to be integrated into a strategic management control system.

Consequently as acceptable Green Corridor Balanced Scorecard should again allow four perspectives including all important perspectives for green transport corridors and should additionally focus on the underlying network and cluster properties of a corridor. One possible approach for such a concept for a green corridor balanced scorecard which is in line with a controlling concept for supply chains has been elaborated and proposed by Prause (2014a). In this model four perspectives appear and two of them are dedicated to cooperation like in Weber's model.

Of special interest is the perspective concerning cooperation quality because here the "soft factor" aspects are covered. In accordance with the already discussed topics the model comprises four indicators for cooperation quality (Prause, 2014a):

- Openness

- Trust level

- Transparency level

- Conflict level.

Since all mentioned indicators have to be measured the usability of a green corridor balanced scorecard concept heavily depends on practical measures. Weber (2002) proposed for the measurement of trust level and conflict level and other measures are discussed in academic literature so that measures for trust and conflict levels can draw on established theories (DeLangen, 2004; Prause, 2010).

In contract the measurement of openness and transparency are rather topics of ongoing scientific discussions (Schnackenberg, 2009; Schnackenberg and Tomlinson, 2014). In the context of this paper openness is more oriented on open access to potential or real stakeholders of the corridor and its institutions and resources, i.e. is rather related to the issue of "harmonized regulations with openness for all actors", whereas transparency is more focussing on the accessibility of information. Nevertheless, the situation is still like Sheila Coronel (2012) pointed out, that there exists still a ratings paradox for openness and transparency with many measures but no "Super Index".

Despite the fact that there is no "super index" there are general measures for openness and transparency which are agreed among experts concerning governmental systems and which include the disclosure of spending and procurement data, open information portals for stakeholders and open meetings of institutions (Coronel, 2012).

In the context of the frame conditions of a green corridor there can be added the disclosure of service and pricing information of stakeholders in the corridor, information about received orders and turnovers according to stakeholders and company size in order to get aware about participation of SME in corridor services as well as information about the utilisation rate of common corridor resources compared to all resources. This is of special interest for the common corridor IT system because here a measure expressing the percentage of all corridor orders which are handled by the corridor IT system compared to those orders still handled by company owned IT systems can be interpreted as an acceptance rate of the corridor resources together with their regulations.

\section{Balanced Scorecards for Green Transport Corridors}

Coming back to Weber's (2002) integrated supply chain balanced scorecard approach, which was discussed in chapter 2, the cross-company aspects of a supply chain were covered by the two perspectives cooperation intensity and cooperation quality, describing the "hard factors" and the "soft factors" related to the cooperation in the supply chain. Since these two cooperation perspectives apply to green transport corridors in the same way like for supply chains it is recommendable to keep these two network perspectives in a controlling concept for green corridors.

More complicated is to decide whether the financial and process perspectives are appropriate from the controlling point of view for green corridors. The KPI system of the EWTC "Green Corridor Manual" used the "sustainability" perspective covering economic, ecologic and social aspects, thus from the EWTC understanding the financial and process perspective is integrated into the sustainability perspective. Consequently, it makes sense to take the "sustainability perspective" with the full EWCTKPI system as a third perspective for a tentative green corridor scorecard.

In the classical balanced scorecard approach of Kaplan and Norton (1996) a fourth perspective is introduced. By comparing classical balanced scorecard approach with the proposal of Weber (2002) it turns out that learning, client and growth perspectives are missing. Since a green corridor enjoys a 
network or a tubular cluster structure, development and growth represent an important element for such a construction due to inter-organizational knowledge transfer among the network partners, the generation of innovations and new service design solutions for the clients as well as the implementation of process and organizational innovations in the corridor. Therefore, it is recommendable to integrate a growth perspective as the fourth dimension for the green corridor.

By summing up the done reflections and results concerning a Green Corridor Balanced Scorecard the four perspectives together with a set of possible indicators lead to the following situation:

- Sustainability perspective

○ Economic efficiency

- Environmental efficiency

- Social efficiency

- Growth perspective

- Innovation activities

- New services

- Green corridor stakeholder fluctuation

- TO of new services

- Cooperation intensity

- Data exchange

- Coordination needs

- Cooperation quality
○ Openness
- Trust level
- Transparency level
- Conflict level

This balanced scorecard includes all important perspectives for green transport corridors and focusses on the underlying network properties of a corridor. Furthermore, it constitutes the KPI system of the EWTC2 project. The set of indicators is not complete and also the type of measurement and evaluation of the indicators is still open, but nevertheless the presented concept for a green corridor balanced scorecard is a further development and in line with a controlling concept for supply chains. In this sense the presented balanced scorecard represents an important stepping stone for a controlling concept for green corridors, but it is obvious that further research has to be done to mature a complete controlling concept for green transport corridors.

\section{Conclusions}

The concept of Green Transport Corridor plays an important role in the European transport policy but a powerful management control system for those corridors in still missing. Even for supply chains a literature review reveals that no integral theory or conceptual framework papers about supply chain controlling exist in the leading English speaking journals. The situation is slightly different among German speaking scholars, since a German supply chain controlling concepts exists in German literature.

By understanding green corridors as a regional network, which enjoys supply chain characteristics, methods of network-oriented controlling and supply chain controlling can be applied. In network-oriented controlling the balanced scorecard concept of Kaplan and Norton (1996) has been successfully adapted and further developed. An important step towards supply chain and network-oriented controlling was established by Weber (2002), who created a cross-company balanced scorecard for a supply chain, which consisted of four perspectives including the financial perspective, the process perspective, the two perspectives of cooperation intensity and cooperation quality. The two cooperation perspectives describe the "hard factors" and "soft factors" of the cooperation.

Based on these results the paper tries to integrate the results and experiences of important green corridor initiatives in the Baltic Sea Region in order to create green corridor balanced scorecard. First, the KPI system of the EWTC project is integrated into the scorecard in order to safeguard the "sustainability" perspective. Second, the growth perspective is integrated into the green corridor balanced scorecard in order to represent development and growth as important elements of such a corridor, since interorganizational knowledge transfer, the generation of innovations and new service design solutions for the clients as well as the implementation of process and organizational innovations in the corridor are of vital importance. Finally, a fully developed balanced scorecard for green transport corridors needs not only the definition of appropriate perspectives, but it also requires a set of powerful indicators together with types 
of measurement and evaluation of the indicators. All these topics are still subject to research so that the presented balanced scorecard constitutes a first step towards a controlling concept for green corridors.

\section{References}

1. Ackermann, I. (2003). Using the balanced scorecard for supply chain management - Prerequisites, integration issues, and performance measures. In: Seuring, S.; Müller, M.; Goldbach, M.; Schneidewind, U. (Hrsg.): Strategy and organization in supply chains. Heidelberg and New York, 289-304

2. Coronel, S. (2012). Measuring Openness: A survey of transparency ratings and the prospects for a global index, 30.10.2012, http://www.freedominfo.org/2012/10/, accessed: 13.07.2014

3. Daduna, J.; Hunke, K.; Prause, G. (2012). Analysis of Short Sea Shipping-Based Logistics Corridors in the Baltic Sea Region. Journal of Shipping and Ocean Engineering, 2(5, Serial Number 8), 304 319.

4. DeLangen, P. W. (2004). The Performance of Seaport Clusters. TRAIL Thesis Series, No. T2004/1. ISBN 90-5892-056-9.

5. Evangelista, P. (2002) The role of ICT in the logistics integration process of shipping lines. Pomorski zbornik 40.1 (2002): 61-78.

6. EWTC II Green Corridor Manual. (2012). Green Corridor Manual - Task 3B of the EWTC II project.

7. Göpfert, I. (2013). Logistik, Verlag Franz Vahlen, 3rd Edition, München

8. Green Corridor (2010). Regeringskansliet - Government Offices of Sweden. Green Corridors. 15.06.2010

9. Hess, T. (2002). Netzwerkcontrolling: Instrumente und ihre Werkzeugunterstützung. Wiesbaden

10. Hippe, A. (1997). Interdependenzen von Strategie und Controlling in Unternehmensnetzwerken, Wiesbaden

11. Hunke, K.; Prause, G. (2013). Management of Green Corridor Performance. Transport and Telecommunication, 14(4), 292 - 299.

12. Hunke, K.; Prause, G. (2014). Sustainable supply chain management in German automotive industry: experiences and success factors. Journal of Security and Sustainability Issues, 3(3), $15-22$.

13. Info Broker (2012). A key to efficient performance with as small ecological footprint as possible. EWTC II, Net.Port Karlshamn

14. Kaplan, R.; Norton, D. (1996). The Balanced Scorecard. Translating Strategy into Action, Boston.

15. Kersten, W., Boeger, M.; Schroeder, M.; Singer, C. (2007). Developing Regions through Spatial Planning and Logistics \& ICT competence - final report. As part of the publication series of the EU project LogOn Baltic, Turku School of Economics, report no. 1:2007, Turku.

16. Kron, E.; Prause, G. (2008). LogOn Baltic aggregated ICT Survey Report, Turku School of Economics, Turku 2008

17. Kusch, T.; Prause, G.; Hunke, K. (2011). The East-West Transport Corridor and the Shuttle Train "VIKING". Wismar: Wismar University

18. Lange, C.; Schaefer, S.; Daldrup, H. (2001). Integriertes Controlling in strategischen Unternehmensnetzwerken, Controlling 13(2), 75-83.

19. Lee, P.D. (2005). Measuring Supply Chain Integration: A Social Network Approach. Supply Chain Forum: An International Journal 6(2), 58-67.

20. Prause, G. (2010). SME in Service Cluster - A regional Study. In: Kramer, J.; Prause, G.; Sepp, J. (Eds.) Baltic Business and Socio-Economic Development 2007: 3rd International Conference Tallinn, Estonia, June 17-19, 2007 (349 - 360). Berlin: Berliner Wissenschafts-Verlag

21. Prause, G. (2014a). CONTROLLINGING CONCEPTS FOR GREEN TRANSPORT CORRIDORS, Proceedings of the 14th International Conference "Reliability and Statistics in Transport and Communication". Riga, 15.-18.October 2014, forthcoming

22. Prause, G. (2014b). Sustainable Development of Logistics Clusters in Green Transport Corridors, Journal of Security and Sustainability Issues, 4(4), forthcoming

23. Prause, G.; Hunke, K. (2014a). Sustainable Entrepreneurship along green corridors. Journal of Entrepreneurship and Sustainability Issues, 1(3), 124 - 133.

24. Prause, G.; Hunke, K. (2014b). Secure and Sustainable Supply Chain Management: Integrated ICTSystems for Green Transport Corridors. Journal of Security and Sustainability Issues, 3(4), 5 - 16.

25. Prause, G.; Kron, E.; Beifert, A. (2010). Final ICT Report of the project "Innovation Network Logistics Cluster Wismar Seaport”, Wismar 2010 
26. Sander, N.; Premus, R. (2002). IT applications in Supply Chain Organisations: a link between competitive priorities and organisational benefits, Journal of Business Logistics, Vol. 23, No. 1, 6583.

27. Sarkis, J. (2001). Introduction. Greener Management International 35(3), 21-25.

28. Schnackenberg, A. (2009). Measuring Transparency: Towards a greater Understanding of systematic Transparence and Accountability, Weatherhead School of Management, Case Western Reserve University

29. Schnackenberg, A.; Tomlinson, E., (2014). Organizational Transparency: A New Perspective on Managing Trust in Organization-Stakeholder Relationships. Journal of Management DOI: $10.1177 / 0149206314525202$

30. Seuring, S. (2006). Supply Chain Controlling: summarizing recent developments in German literature, Supply Chain Management: An International Journal, Vol. 11(1), 10 - 14.

31. Seuring, S.; Müller, M. (2008). From literature review to a conceptual framework for sustainable supply chain managmement, Journal of Cleaner Production, Vol. 16, 1699 - 1710.

32. Sydow, J.; Möllering, G. (2009). Produktion in Netzwerken, Verlag Franz Vahlen, 2nd edition, München 